Canadian University Music Review

Revue de musique des universités canadiennes

\title{
Toward a Sociology of Musical Styles
}

John Shepherd

Numéro 2, 1981

URI : https://id.erudit.org/iderudit/1013747ar

DOI : https://doi.org/10.7202/1013747ar

Aller au sommaire du numéro

Éditeur(s)

Canadian University Music Society / Société de musique des universités

canadiennes

ISSN

0710-0353 (imprimé)

2291-2436 (numérique)

Découvrir la revue

Citer cet article

Shepherd, J. (1981). Toward a Sociology of Musical Styles. Canadian University Music Review / Revue de musique des universités canadiennes, (2), 114-137.

https://doi.org/10.7202/1013747ar

All Rights Reserved (C Canadian University Music Society / Société de musique des universités canadiennes, 1981
Ce document est protégé par la loi sur le droit d'auteur. L'utilisation des services d'Érudit (y compris la reproduction) est assujettie à sa politique d'utilisation que vous pouvez consulter en ligne.

https://apropos.erudit.org/fr/usagers/politique-dutilisation/ 


\title{
TOWARD A SOCIOLOGY OF MUSICAL STYLES*
}

\author{
John Shepherd
}

The idea that different groups and societies create and appreciate their own stylistically distinguishable kinds of music is not one that would be likely to invite dissension from musicians or sociologists. Neither, on the face of it, is the assumption that the stylistic characteristics of these different kinds of music might have some connection with what may be loosely termed the "cultural background" of their creation. As Lévis-Strauss has argued with respect to language:

Between culture and language there cannot be no relations at all .... If there were no relations at all that would lead us to assume that the human mind is a kind of jumble that there is no connection at all between what the mind is doing on one level, and what the mind is doing on another level (1968:79).

That there are connections between "what the mind is doing on one level, and what the mind is doing on another level" is not difficult to illustrate on a prima facie basis where music is concerned. Is it a complete coincidence, for example, that functional tonality arose from the fervor of an intellectual and artistic movement (the Renaissance) which arguably laid the foundations for modern capitalist society? Is it a complete coincidence that alternatives to that musical "language" began to be offered at a time when the "reality" of three-dimensional

\footnotetext{
*An earlier draft of this paper was presented at a conference on the Sociology and Anthropology of Music, Keele University (U.K.), May 1979. Certain passages from the early part of the paper are drawn from John Shepherd, "Music: and Social Control: An Essay on the Sociology of Musical Knowledge," Catalyst, No. 13 (1979), 1-54. I am grateful to the editor of Catalyst for permission to reprint this material.
} 
perspective in painting was under attack, and when classical physics was facing a very considerable crisis? Is it completely without foundation that many people have seen in the rise of Afro-American-influenced popular musics social implications of great importance?

It is, of course, possible to argue that the cultural and social implications of different music styles are completely associative in nature. That is, that although there are connections between what the mind is doing on different levels, a particu'ar music style carries the cultural and social implications it does only because the group or society in question externally imposes a set of meanings or significances on the music in a manner completely arbitrary to the music's basic structure. The argument is that any kind of music will serve a group or society provided the music is stylistically distinguishable from all others; there is nothing internal to the basic structure of the music, in other words, which predisposes it to impart any one kind of significance above all others.

In contrast, it is also possible to argue that the internal structure of a musical style is of itself significant. This is not necessarily to assume that the significance of music is located in some form of asocial, ultimate reality, however. It can be asserted that because people create music, they reproduce in the basic structure of their music the basic structure of their own thought processes. If it is accepted that people's thought processes are socially mediated, then it could be said that the basic structures of different styles of music are likewise socially mediated and so socially significant.

It is in the light of this second possibility that a sociology of musical styles becomes a viable proposition, at least in theory. If musical styles have an inherent social significance, then it should be possible to demonstrate that significance by carrying out musical analysis in terms of the social reality which gave birth to and is articulated by a particular musical style.

Such analyses are notably absent from both the musicological and sociological worlds. Surface reasons for the scant attention given to the sociology of music (as opposed to the sociology of musical life) are not difficult to find. Few sociologists feel themselves to be competent in a discipline which requires a significant degree of technical knowledge as well as, preferably, some first-hand experience as a practitioner. Musicologists, 
on the other hand, repelled by what they see as unending waves of pseudo-scientific jargon, have apparently decided that the area should be left well alone. The art of musical analysis is well established, and musicologists see in sociology no good reason for changing their methods or approaches where traditional analysis is concerned. But reasons for the neglect of a sociology of musical styles go deeper than sociologists' lack of musical knowledge, or musicologists' perhaps healthy scepticism for social "science." This paper seeks to outline the major difficulties which stand in the way of a sociology of musical styles, and to indicate the way in which those difficulties might be overcome.

The first block to a sociology of musical styles derives from the way in which the majority of musicologists subscribe, either implicitly or explicitly, to an elitist view of art. This view of art, it can be argued, forms an integral aspect of the structure of capitalist society.

Capitalist society is usually taken to be characterized by a highly developed division of labor which reinforces a markedly hierarchical class system. These characteristics are in turn taken to be symptomatic of extended centralized lines of social control which alienate many people from their essential natures and preclude them from participating in society to the fullest of their potential. Due to the highly developed division of labor, hierarchical class structure, and centralism of capitalist society, the "intellectual" in all spheres of society has remained very much in the position of producing and defining knowledge for other people. ${ }^{1}$ For the centralized dissemination of knowledge to remain intact in the face of challenge, it is necessary that knowledge be conceived according to the canons of an absolute or objective idealism. It is necessary, in other words, that reality be thought of as "given" rather than socially constructed.

It is precisely with this type of absolute and idealist concept that art has traditionally concerned itself since the time of the ancient Greeks. As far as the modern world is concerned we are told by Raymond Williams that the argument that "an artisi's precepts were ... the 'universals' (in Aristotle's terms) 
or permanent realities" is one which "had been completed in the writings of the Renaissance" (1961:52). And as the same author goes on to point out, it is also an argument which united the otherwise disparate creeds of Classicism and Romanticism:

The tendency of Romanticism is towards a vehement rejection of dogmas of method in art, but it is also very clearly towards a claim which all good classical theory would have recognised: the claim that the artist's business is to read the "open secrets of the universe." A "romantic" critic like Ruskin, for example, bases his whole theory of art on just this "classicist" doctrine. The artist perceives and represents Essential Reality, and he does so by virtue of his master faculty Imagination. In fact the doctrines of "the genius" (the autonomous creative artist) and the "superior reality of art" (penetration to a sphere of universal truth) were in Romantic thinking two sides of the same claim. Both Romanticism and Classicism are in this sense idealist theories of art (ibid.: 56).

This concern with truth as the ultimate aim of art and culture has persisted into the twentieth century, albeit in rather less explicit forms. In his Notes towards the Definition of Culture, for example, T.S. Eliot argues that diversity of cultural activity is essential to the maintenance of a valid spiritual life. Dialectic is a necessary prerequisite for truth:

As in the relation between the social classes, and as in the relation of the several regions of a country to each other and to the central power, it would seem that a constant struggle between the centripetal and centrifugal forces is desirable. ... There should be an endless conflict between ideas for it is only by the struggle against constantly appearing false ideas that truth is enlarged and clarified, and in the conflict with heresy that orthodoxy is developed to meet the needs of time (1948:82).

The complex of arguments associated with an elitist concept of art tends only to be explicitly stated when the concept is faced with a substantial challenge. It could be argued that the first notable challenge to the centralized definition and dissemination of knowledge in post-Renaissance society did not occur until the late eighteenth century, with the rise to power and influence of the middle classes. It is not 
entirely coincidental, therefore, that it was at this time that the notion of art as an approach to essential reality received, in the words of Raymond Williams, "significant additional emphases" (1961:60-61). Faced with a deviant cultural reality, in other words, writers and artists were forced back on the notion that all culture attains to one, indivisible, essential truth.

But this is only the first step in the line of defence, because it is equally possible for the perpetrators of a deviant cultural reality to claim that they too have access to the essential nature of truth. Further, they may claim that their art forms interpret this essential reality more successfully than the traditional art forms with which they vie. Those who produce such traditional art forms are therefore driven firstly to claim that it is their art forms which best reveal the inner nature of essential reality, and then to maintain that it is only a limited number of highly-tuned minds (such as themselves) who are capable of appreciating this reality in an unaided fashion. F.R. Leavis puts this view most explicitly:

In any period, it is upon a very small minority that the discerning appreciation of art and literature depends: it is (apart from cases of the simple and familiar) only a few who are capable of unprompted, first-hand judgement. They are still a minority, though a larger one, who are capable of endorsing such a first-hand judgement by genuine personal response. The accepted valuations are a kind of paper currency based upon a very small proportion of gold (1948:143).

The reverse side of the coin, of course, is a disdain for the critical abilities of the "culturally untutored." Although such disdain is necessarily implicit in the very notion of a centrally defined culture, it is again interesting to note that the attitude became more deeply entrenched at the beginning of the nineteenth century. As Raymond Williams says:

Writers had ... often expressed, before this time, a feeling of dissatisfaction with the "public," but in the early nineteenth century this feeling became acute and general. One finds it in Keats: "I have not the slightest feeling of humility towards the public"; in Shelley: "Accept no counsel from the simple-minded. Time reverses the judgement of the foolish crowd. Contemporary criticism is no more than the sum of 
the folly with which genius has to wrestle." One finds it, most noticeably and extensively, in Wordsworth (1961:51).

Coupled with the belief that art reveals higher truths fathomable only by a minority of superior minds is the idea that these minds are responsible for preserving the cultural values of a society. This idea is as prevalent in the twentieth century as it was in the nineteenth. The early nineteenth-century writer, we are told by Williams, continued

... to insist, in fact, on an Idea, a standard of excellence, the "embodied spirit" of a People's knowledge, as something superior to the actual run of the market. This insistence, it is worth emphasising, is one of the primary sources of the idea of Culture. Culture, the "embodied spirit of a People," the true standard of excellence, became available, in the progress of the century, as the court of appeal in which real values were determined (ibid: 52 ).

Maintaining this line of thought, the twentieth-century writer F.R. Leavis states that:

Upon this minority depends our power of profiting by the finest human experience of the past; they keep alive the subtlest and most perishable parts of tradition. Upon them depend the implicit standards that order the finer living of an age, the sense that this is worth more than that, this rather than that is the direction in which to go, that the centre is here rather than there (1948:143-44).

It is this last line of thought in the complex of arguments under discussion that is most obviously allied to the central dissemination of knowledge in capitalist society. Yet it is important to understand that this line of thought cannot be maintained without the presence of the other two. In other words, unless there are a set of objective values and standards against which all cultural activity can ultimately be judged, and unless it is the case that only a minority are capable of perceiving the essential truth underlying those values, then the legitimacy of the role played by that minority quickly comes into question.

It is further interesting to note that this elitist attitude toward culture is based on the questionable premise that society is divided between those who have inherently superior, and 
those who have inherently inferior, intellects. This premise in turn gives birth to a circular or self-maintaining view of cultural apprehension: it is only those with superior minds who can fathom the ultimate realities of art, yet it is those who can fathom these realities who by definition have superior minds; equally, those with inferior minds cannot fathom the ultimate realities of art, yet it is precisely those who cannot fathom those realities who by definition have inferior minds. This circularity is implicitly acknowledged by T.S. Eliot when he says that "it is an essential condition of the preservation of the quality of the culture of the minority that it should be a minority culture" (1948:107), and through Arnold Schoenberg's famous aphorism that "if it is art it is not for all, and if it is for all, it is not art."

Not surprisingly, the attitudes so far described are to be found in the musical as well as in the literary worlds. The idea that the composer mediates between "the open secrets of the universe" and the music he writes finds classical expression in the work of Victor Zuckerkandl. For Zuckerkandl, musical significance is located in laws which may only be discovered by the composer in objective reality:

It is not that the mind of the creative artist expresses itself in tones, words, colours, and forms as its medium; on the contrary, tone, word, colour, form, express themselves through the medium of the creative mind. The finer that medium the better tone, word, colour, form can express themselves. The greater the genius, the less it speaks itself, the more it lends its voice to the tones, the words, the colours, the forms. In this sense, then, music does write itself - neither more nor less, by the way, than physics does. The law of falling bodies is no invention of the genius of Galileo. The work of the genius consists in bringing the mind, through years of practice, so into harmony with things, that things can express their laws through him (1956:222-23).

A similar view has more recently been expressed by Ruth Gipps. For her, music is a mystic experience founded on truth: 
I know that from one God comes music and all musical gifts. Some of us were composers from the beginning of our lives; we had no choice in the matter, only a life-long duty to make the most of a given talent. This talent may be large or small, but without it a person is not a composer. ... My own conception of God is of a limitless contrapuntal mind; perhaps this concept lacks humanity, but that is my own business. From personal experience I know that mysticism is founded on truth (1975:13).

\section{Consequently:}

No human being has ever created anything. The most that a composer can do is to present to other people, in a comprehensible form, music that already existed. Bach wrote "S.D.G." at the end of works. None of his music was a product of the cleverness of J.S. Bach (ibid.).

The idea that a minority of people are imbued with a special gift of musicality which may subsequently be cultivated into genius is a commonplace in many people's thinking about music, and needs no further comment in the present context. But such belief in the other-worldly nature of musical inspiration, and the ability of only a minority to exploit it in turn leads to the concept of an objective aesthetic. That is, it is assumed that there are a fixed set of musical criteria against which all music can ultimately be judged. Not surprisingly, these criteria tend to be rooted in the musical language of the ruling classes. Leonard B. Meyer, for example, has spent a large part of his working life attempting to extrapolate a universally applicable theory of music from albeit insightful analyses of functional tonality. Again not surprisingly, pre-literate music does not fair very well:

The differentia between art music and primitive lies in speed of tendency gratification. The primitive seeks almost immediate gratification of his tendencies whether these be biological or musical. Nor can he tolerate uncertainty. And it is because distant departures from the certainty and respose of the tonic note and lengthy delays in gratification are insufferable to him that the tonal repertory of the primitive is limited, not because he cannot think of the other tones. It is not his mentality that is limited, it is his maturity (1967:32). 
The tendency to judge all music in terms of functional tonality finds its clearest expression in Ruth Gipps:

The corollary of the truth that all real music comes from inspiration is that all so-called music written without inspiration is not music at all, and the people who write it are not composers. Ranging from the super-intellectual to the wildest woolliest lunatic fringe, we have for years been given performances of worthless nonsense, while real composers have been labelled backward-looking, unenterprising, or unwilling to experiment (1975:14).

Opinions of this sort are not infrequently backed up with arguments of a technical or analytical nature. Marshall Stearns, for example, reports the following conversation with a friend about jazz:

"Jazz," he told me one evening, "is unnatural, abnormal and just plain unhealthy." I know of no effective way to answer this sort of pronouncement on any human activity. When pressed for reasons, however, he fell back on more rational assertions: "The harmonies of jazz are childish, the melodies are a series of clichés, and the rhythms are monotonously simple." Here is something technical and specific. What is more these criticisms are reasonably typical and comprehensive. Since my friend (and others like him) occupies an important position in the world of music on the strength of his unquestioned merits, his comments should be taken seriously (1956:183).

Since, as Henry Pleasants puts it, the musical "establishment is concerned with the preservation of what it regards, sincerely, I think, as immutable cultural criteria" (1969:118), its criticism of music which does not conform to pre-ordained technical or analytical criteria also tends to carry an accompanying moralistic component. This tendency toward denunciation of various forms of jazz, rock, and "pop" music is so well known that it hardly requires substantiation. One need only refer, for example, to Merriam's cataloguing of the tirade launched against jazz in the United States between the 1920s and 1940s (see Merriam 1964: 241-42), or, as far as "pop" is concerned, to the unfailing Ruth Gipps: 
In fact, the pop craze has done much serious harm to thousands. Every time a misguided teacher uses commercial pop in school the kids concerned are being led from the good and spiritual in their natures towards the evil and hypocritical (1976: 17).

It now becomes clear why aestheticians and music theorists will at all costs refrain from assigning music (by which they almost without exception mean "serious" music) an inherently social significance. For if the significance of music is taken to be socially located, then it must be understood to form an aspect of the socially constructed reality of the group or society responsible for producing the music in question. In other words, the music can only be legitimately understood in terms of the categories of analysis which themselves form an aspect of the reality of that particular group or society, and consequently there can be no question of recourse to the notion that musical significance is derived from the "open secrets of the universe" or some other form of mystical, other-worldly truth.

Once the significance of music is taken to be socially located, the circle of argument predicated on the notion of inherently superior and inferior minds is broken. Difference in cultural values is due not so much to questions of inherent intelligence as to the existence of socially constructed and different cultural criteria which not infrequently display a mutual incompatibility. ${ }^{2}$ With this central pillar of the elitist position removed, the right of the institutionalized musician or aesthetician in capitalist society to approach most music in terms of certain idealistically conceived categories thus comes into serious question. Consequently, the propensity for such musicians and aestheticians to attempt to impose a certain kind of musical knowledge on the rest of society would also come into question.

The fact that an acceptance of the social mediation of music might result in a weakening of role-security is significant, but is perhaps not the most telling point against such acceptance. Quite clearly, any assertion that the reality of knowledge of a society is socially constructed not only brings into question the notion of absolutely and objectively conceived knowledge, but thereby questions the right of one group in society to use that notion in order to attempt a centralized manipulation and control of knowledge and values for all other groups. Because 
centralized social structures ultimately depend for their survival on such modes of cognitive manipulation and control, questioning of the sort indicated would ultimately result in the scrutiny of the entire centralized structure of capitalism.

The connection may to some people seem a distant one, but it is more than possible that the lack of a disposition on the part of musicians and aestheticians to accept the significance of "serious" music as socially located is due to the fact that such acceptance would implicitly require a questioning of the social and political structure within which we all live. Not only would it mean accepting that the various forms of jazz, rock, and "pop" music are equally as "good" as serious.forms, but it would also mean accepting the social and moral relativity of the deviant realities they have come to represent and articulate.

It may be the institutional restraint just outlined which has prevented Leonard B. Meyer, perhaps the most intellectually honest of musicologists, from seriously exploring the possibility that the significance of music is, indeed, inherently social. His quest for a universally applicable theory of music has always been partially circumscribed by adherence to approaches which are essentially psychologistic, a tendency which can be illustrated by reference to his most recent book, Explaining Music.

Meyer, in fact, admits to this circumscription in a roundabout way. At the beginning of Explaining Music the author states: "As I intend the term, criticism seeks to explain how the structure and process of a particular composition are related to the competent listener's comprehension of it" (1973: ix). The nature of this comprehension is expounded on toward the end of the book:

A competent listener perceives and responds to music with his total being. ... Through such empathetic identification, music is quite literally felt, and it can be felt without the mediation of extramusical concepts or images. Such kinesthetic sensing of the ethos or character of a musical event is what the term ethetic refers to (ibid.: 242). 
It is precisely this ethetic relationship, which stands at the heart of musical apprehension, that is problematic for Meyer: "Ethetic relationships are unquestionably important ... [but] are hard to analyze with rigor and precision. ... [There is an] absence of an adequate theory of ethetic change and transformation" (ibid.: 245-46). Again: "The analysis must end here . . [because] the rigorous analysis of ethetic relationships is beyond my knowledge and skill (ibid.: 267).

The remedy, it would seem, is in Meyer's own hands. In his opening chapter, "On the Nature and Limits of Critical Analysis," the author draws a basic distinction between critical analysis and style analysis. Whereas critical analysis is concerned with the singular and idiosyncratic, style analysis "is concerned with discovering and describing those attributes of a composition which are common to a group of works" (ibid.: 7). Theory, moreover, "endeavors ... to discover the principles governing the formation of the typical procedures and schemata described in style analysis" (ibid.: 7-8). To complete the relationship: "Critical analysis uses the laws formulated by music theory . . . in order to explain how and why the particular events within a composition are related to one another" (ibid.: 9).

It could be assumed from this last statement that the principles and laws of music theory would be of crucial importance to the development of a critical method. But apparently this is not so. In being required to explain why the melodies of Palestrina, for example, display a certain structural feature, Meyer suggests one answer "with a general law of some sort" (ibid.: 8). This law might be "the Gestalt law of completeness, which asserts that the human mind, searching for stable shapes, wants patterns to be as complete as possible" (ibid.). Beyond this, however, Meyer does not think it necessary to go. There is thus no need to explore the processes inherent in the search for stable shapes: "I doubt that the explanation of musical practice needs to be pushed back this far. As a rule we are, I think, satisfied with the least inclusive law which will account for the events described" (ibid.).

But satisfaction is surely the one thing Meyer does not attain. In one breath he tells us that "the rigorous analysis of ethetic relationships is beyond my knowledge and skill," and in another he strongly implies that the psychological processes which he clearly sees as important to those ethetic relationships - do not themselves require that same "rigorous analysis." 
It is possible to trace this conundrum, not only to the institutional restraint already discussed, but to a central difficulty in understanding the functioning of music. Unlike words and pictures, the significance of music cannot, as Meyer has already said, be approached through "the mediation of extra-musical concepts or images." If, indeed, music can be said to have "meaning" (given the usual referential significance of that term) then, in the minds of most musicians and musicologists, it is undoubtedly to be located within the internal structuring of the particular composition in question. And since music both originates and is efficacious within the minds of people, it can be assumed: (a) that there must be a conformance between musical structures and the structure of the human mind, and consequently (b) that this structure can ultimately be revealed through the analysis of any musical idiom. Both these assumptions are implicit in Meyer's thought:

In music, psychological constants such as the principles of pattern organization, the syntax of particular styles, and typical schemata ... constitute the rules of the game.... For any given musical repertory, the "rules" determine the kinds of pattern that can be employed in a composition (ibid.: 14).

It follows, then, that music can satisfactorily be explained in terms of itself, and it is symptomatic that, in supporting his idea of the "least inclusive law," Meyer incorporates Mario Bunge's view that "every system and every event can be accounted for ... primarily in terms of its own level and adjoining levels" (quoted in ibid.: 8).

Since, on the surface, there would appear to be nothing fallacious in this line of argument, Meyer looks elsewhere for the cause of his difficulties with ethetic relationships. He apparently concludes that the cause is to be found in the impossibility of distinguishing between psychological constants and the conventions of a particular musical idiom:

In theory, it is possible to distinguish between archetypal patterns and schemata. The former would be those patterns which arise as the result of physiological and psychological constants presumed innate in human behavior. The latter would be those norms which were the result of learning. But the distinction breaks down in practice. For most tradi- 
tionally established norms have some basis in innate constants, and, on the other hand, patterns derived from innate constants become parts of tradition. This being the case [Meyer concludes] the terms will be used more or less interchangeably (ibid.: 214).

It is not to be disputed that psychological or physiological constants might be incorporated in all forms of musical expression. But since, on Meyer's own admission, the constants are assimilated in, and become indistinguishable from, the norms of specific musical idioms, would it not be more fruitful to seek the basis of ethetic relationships in these different and identifiable norms? Here, however, the difficulty of musical "meaning" comes into play again, because if it is assumed that musical significance is to be located in the structuring of particular norms, then it is not a very big step to further assume that this structuring is rooted in the extra-musical "beliefs" and "ideas" of the appropriate culture.

Even if a musicologist or aesthetician overcomes the institutional restraint already described, and seriously entertains the possibility that the significance of music is, indeed, inherently social, there remains the difficulty of how music can have that significance. On the one hand, music would seem to have a significance which is located outside and beyond itself in society at large. On the other, most musicians and musicologists remain convinced that the significance of music has a great deal to do with its internal structure. That is why they do analysis. A hint as to the cause of this difficulty is given by two sociologists. Terry Lovell, for example, has stated:

Content analysis - the categories of analysis being drawn from the categories of social life itself - is biased in favour of the representational arts. We have little in the way of sociology of music... Sociology of "pop" music is uniformly restricted to the analysis of the lyrics. . . Where there are no lyrics we may get trivial results" (1972: 329).

Again, Hugh D. Duncan has said, in ironic mood, that "communication ... must be explained by everything but 
communication ...; it must have, as we read so often, a 'referent'” (1968: 31).

To translate these insights into everyday terms, a symbol has meaning for most people because it refers to something outside itself. Pictures have meanings because they refer to something in physical reality, and words have meaning because they refer to concepts and ideas. But the suggestion that a piece of music has meaning primarily because of extra-musical references is, as already suggested, inadmissible to most musicians. The logical alternative on the part of musicologists and aestheticians is thus to look for the meaning of music within the structure of individual pieces, an alternative whose strictest formulation, as Meyer indicates, is to be found in the attitude of the absolutists:

The absolutists have contended that the meaning of music lies specifically, and some would assert exclusively, in the musical processes themselves. For them musical meaning is non-designative. But in what sense these processes are meaningful ... they have been unable to state with either clarity or precision. ... This failure has led some critics to assert that musical meaning is a thing apart, different in some unexplained way from all other kinds of meaning. This is simply an evasion of the real issue (1956: 33).

The real issue can be stated in terms of the following comparison. Because their meaning is "located outside them," words and pictures may be thought of as "carrying" their meaning and "giving" it to the recipient. The symbol, in other words, survives the divulgence of its message. If, on the other hand, musical meaning is acknowledged to lie within the musical process itself, then in "giving away" that meaning, a piece seemingly compromises the very being or essence responsible for the meaning in the first place. As Susanne Langer has put it, the absolutists "seem to feel that if musical structures should really be found to have significance, to relate to anything beyond themselves, those structures would forthwith cease to be musical" (1960: 236).

This difficulty results from confusing a symbol which has no obvious referent in the world of objects and ideas with one which is incapable of communicating outside itself. Music would seem to fall within the former but not, as the absolutists would imply, the latter category. It is this distinction which 
facilitates the psychologistic theories of musicologists such as Meyer and aestheticians such as Langer. As already indicated, psychologistic theories for the significance of music are broadly based on the premise that, since all music originates in the minds of individual people, and since all minds are assumed to possess similar psychological characteristics, there will be a conformity of patterning or structure between all music and all minds. Consequently, all minds are presumed to be suitably predisposed for the superimposition of the particular structure that constitutes a piece, and there is no longer any need to have recourse to the notion of symbols which divest themselves of externally referential meanings. Significance is imparted by another method, structural rather than referential.

The emphasis put by psychologistic theories on the conformity of structuring between minds and music might, on the face of it, seem to overcome the difficulty highlighted in the absolutists' position. The conformity guarantees a degree of "outerness" for music, because the music is efficacious within minds which are essentially external to its structure. However, as Meyer himself has implied, purely psychologistic theories are not without their problem. They do not seem to explain musical significance convincingly.

The reason for the ultimate inadequacy of psychologistic theories is to be located, in Terry Lovell's words, in "the categories of analysis ... drawn from the categories of social life itself." I have argued elsewhere (see Shepherd, et al. 1977: 7-34) that the categories of analysis fundamental to the ways of thinking of many people in capitalist society are simply unsuited to a full and adequate understanding of the musical process. The absolutists' position, for example, is based on the assumption that because music does not obviously refer "outside" itself to the material and concrete world, its "content" must be contained "inside" itself. The absolutist, in other words, must contradictorily assert that since the content of music is not located in the outside, physical world, it must be found inside in the form of the music.

Psychologistic theories get over the difficulty of asserting that the content of music is its form by involving another category, that of the psychological or "mental." Psychologistic theories state, in short, that the content of music is to be found outside the form in the mental processes common to all individuals. The only problem with this approach is that mental 
processes are usually taken to belong very much to the inner world which stands in stark opposition to the material and physical world that the absolutist is at such pains to eschew. Formulated in these terms, psychologistic theories do not guarantee music an "outerness" where significance is concerned, they only guarantee it in the sense that music communicates beyond itself to people. The theories might point to the way in which music imparts its significance, in other words, but they say nothing about the substance of that significance. As with absolutist theories, significance is restricted to the inner world of form.

It should be emphasized that this argument is not based simply on a play on words. By examining their origins - and I have carried out this examination elsewhere (see ibid.: 18-24) it can be demonstrated that the categories of "form" and "content," "inner" and "outer," "mental" and "physical" are dialectic, and therefore structural correlates of one another. Indeed, there would seem to be in modern capitalist society a bivalent cognitive system which can be interpreted in any number of different ways at the level of concrete concepts and words. The system can quite easily be extended to include categories such as "emotional" and "intellectual," for example, "subjective" and "objective," or even "female" and "male." When psychologistic theories assert that the content of music is to be found outside the form in mental processes, therefore, they would seem to be restricting the whole question of significance in music to one side of the cognitive system mentioned, and thereby emasculating music as a genuine and potent phenomenon in the world. They are, if the phrase can be excused, committing a structural tautology.

The view that the meaning or significance of music is inherently social overcomes the inadequacy of psychologistic theories by acknowledging that music does, indeed, have a significance of substance to impart. The significance of a piece of music lies in the way its internal structure both reflects and creatively articulates the structure of the group or society in which it was conceived. It is because the minds of individual people also reflect and creatively articulate the structure of those people's group or society that they are suitably predisposed to receive the significance a piece of music has to impart. Society, in other words, is creatively articulated "in" and 
"through" the dialectic interaction of people and symbols. Music is but one mode of symbolic communication.

It is possible to indicate a vital connection between the institutional restraint referred to in the first half of this paper, and the aesthetic difficulty with the significance of music which has just been discussed. Because the notion that music forms an integral aspect of socially constructed reality is, as we have seen, totally incompatible with the idea that musical significance is derived from the "open secrets of the universe," there can be no question, as it were, of a reverse information flow by which society informs the composer. Rather, the mass of people are informed, edified, and improved through the composer's insights into truth. Now neither Langer nor Meyer make any explicit reference to essential truth or a higher reality. But they maintain a unidirectional information flow from a revised form of idealist truth to society at large by locating the significance of music in the "psychological constants" (Meyer 1973:14) or "psychological 'laws of rightness'" (Langer 1960:240), which are common to all people, but which only the composer is able to interpret with any degree of insight. To this extent Langer's and Meyer's theories remain implicitly elitist. While, therefore, they are able to distinguish between a symbol which has no obvious referent in the world of objects and ideas on the one hand, and one which is nevertheless "informationally open" on the other they are constrained to severely restrict the degree of that openness. Although it is admitted that music may refer outside itself to the mental world, it is implicitly denied that it can refer outside to the external symbolic interaction which is arguably responsible for a large measure of that world.

A belief in the inherently social significance of music not only removes the central pillar of the elitist's position, therefore, but transcends the strict psychologistic delimitation of mental processes responsible for the aesthetic difficulty discussed in the second half of this paper. Inherent in that delimitation is the implication that social phenomena result from the collective interaction of physiologically pre-determined consciousnesses, rather than from the interaction of consciousnesses which are 
socially mediated. It is in this way that the psychologistic delimitation of mental processes becomes essential to an elitist view of musical processes.

It would seem that, if musicologists can overcome the institutional and aesthetic difficulties outlined in this paper, they should be able to proceed to a sociology of musical styles, and therefore give musical analysis added significance. It is not difficult, for example, to suggest structural parallels between capitalist society and functional tonality. Functional tonality has one note, the key-note, which is more important than all others. These others, in their turn, have an order of importance. This hierarchy of fundamental notes (or "fundamentals") can be said to parallel the hierarchical nature of our own society. Again, all the other notes in functional tonality tend magnetically toward the key-note. In any particular piece, the desire to end in a satisfying manner on the key-note seems to make that note the controlling factor in pre-determining the placement of all other notes. It is as if the other notes are pre-existing atoms, to be placed at will in a piece in the same way that workers in capitalist society are seen as individual sources of labor to be placed at will in a pre-determined economic system.

Although a theoretical case has been made for such parallels, their satisfactory substantiation on closer inspection becomes more difficult. ${ }^{3}$ It is perhaps because both musical and social processes are so highly fluid that socio-musical analysis seems to slip all too easily between the fingers. Again, the establishing of such parallels pre-empts many questions of social theory. Is music epiphenomenal to the social process in the sense of forming a "symbolic superstructure" that is determined by a "political-economic infrastructure," for example? Or is music an equal partner in the social process, capable of contributing creatively to the social reality of which it forms a part?

Given an adequate airing of such problems, it should be possible to move toward a sociology of functional tonality as a musical style or "language" that includes more detailed analyses of individual periods, composers, and pieces than has hitherto been possible. However, once an attempt is made to 
examine the musics of other groups and societies, additional problems arise. We all still live within a society that is overwhelmingly capitalist in its organization. To conduct a sociological analysis of the music of those who have political and economic power in that society in a hermeneutically satisfactory manner should not, essentially, be problematic. But once attention is shifted even as close as to the "popular" musics of our own society, the potential for ethnocentric analysis becomes considerable. Marshall Stearns's friend saw in jazz only "childish harmonies," "clichéd melodies," and "monotonously simple rhythms," for example. He was seemingly deaf to the rich and complex melodic, harmonic, and rhythmic inflections which characterizes so much Afro-American music, and is responsible for a large part of its significance.

Even assuming that it is possible to reconstitute the socio-musical realities of other groups and societies in a hermeneutically satisfactory manner, there still remains the related problem of whether those realities can legitimately be expressed in the highly explicit and literate terms required by the academic world. Mary Douglas has indicated. the dangers of explicit analysis for ethnology in general:

The anthropologist who draws out the whole scheme of the cosmos ... does the primitive culture great violence if he seems to present the cosmology as a systematic philosophy subscribed to consciously by individuals. We can study our own cosmology - in a specialised department of astronomy. But primitive cosmologies cannot be rightly pinned out for display like exotic lepidoptera, without distortion to the nature of a primitive culture (1970:110-11).

It is easy to imagine distortions of this sort occurring in the analyses of other people's musics. Even if it were possible to identify explicitly the structural significance of the various melodic, harmonic, and rhythmic inflections to be found in performances of the rural blues, for example, it is questionable whether that significance should be spelled out with quite the perspicacity which normally underlies an analysis of the complex melodic, harmonic, and rhythmic structures to be found in a Bach fugue or a Beethoven symphony.

The gradual growth and increasing respectability of ethnomusicology as a discipline would seem to point to a 
growing awareness by musicologists of culturally relative values and criteria, and so of the problems likely to be encountered in undertaking a sociology of different musical styles. Yet perhaps it is because they are so far removed from home, and thus unlikely to challenge the ideological status quo, that musicologists are more disposed to recognize the relative musical and cultural worth of pre-literate musics. For these same musicologists still feel unable to extend a similar courtesy to different musical traditions within our own society. FrançoisBernard Mâche achieves the most explicit of contradictions in the same article, for example. In one breath we are told that "sound recording . . . brought to ears which . . . were willing to hear ... the voices of other musical civilizations, thus calling to mind the relativity of aesthetic dogma" (1973:108), and in another that the output of "serious" music "is almost insignificant ... as compared with the vast mass of sonorous banality liberated by the advent of the music industries" (ibid.: 101). Pre-literate music is just fine. Popular music is not so fine.

Such attitudes are implicit in the curricula of university and many school music departments, especially in the United Kingdom. Ethnomusicology is to be found in the undergraduate programs of some university music departments, most notably in North America. But apart from that, it would seem that curricula are formed almost exclusively around music of the Western concert tradition.

It is not until musicologists face squarely the elitism inherent in such attitudes and policies that a sociology of musical styles will become a serious possibility. Perhaps for this reason, a good starting point for a sociology of musical styles would be not only functional tonality, but the various forms of Afro-American music which have become such a vital force in modern-day society. These Afro-American forms would raise all the difficulties referred to in this paper, yet their comparative accessibility, as well as the comparative accessibility of the people who create and appreciate the music, would make for easier assessment of solutions offered to those difficulties.

It is clear that if the sociological analysis of musical styles is to become an identifiable area of research, there needs to be co-operation on the part of musicologists and sociologists. No one person can be expected to grasp the fundamentals of both disciplines with adequate depth. Musicologists need the help of 
sociologists both in confronting the methodological issues referred to earlier, and in undertaking the analysis of social structures. Sociologists need the help of musicologists in understanding the genuine complexities of musical analysis. Barriers between the two disciplines need to be broken down. Sad to say, it is musicologists who have shown the greatest reticence in this area. 


\section{NOTES}

1. To make this statement is not to indicate a belief in a consensual society. The intellectual (by which is meant any person in a position to legitimate any form of knowledge) still centrally defines knowledge for his group, even if that knowledge conflicts with the knowledge of other groups, whether at the same or a lower or higher level in the overall hierarchic structure.

2. Although, of course, it should not be forgotten that the different realities exist because of the growth of a cultural elite traditionally associated with those who hold political and economic power in society. It is, therefore, rather hypocritical of this elite to criticize the cultural values of dispossessed groups, because it is ultimately through the growth of this elite that those values came into existence in the first place. In short, an elite of necessity implies the existence of dispossessed groups.

3. An attempt at such substantiation has been made in Shepherd, et al. 1977:71-111.

\section{REFERENCES}

DOUGLAS, M.

1970: Purity and Danger. Harmondsworth, Middlesex: Penguin Books.

DUNCAN, H.D.

1968: Symbols in Society. London: Oxford University Press. ELIOT, T.S.

1948: Notes towards the Definition of Culture. London: Faber and Faber.

GIPPS, R.

1975 "A Personal Credo," Composer, No. 54, 13-14.

1976: "The Use of Trendy 'Amplified Pop' in School Music Classes," Incorporated Society of Musicians Music Journal, XLII/3, 17. LANGER, S.

1960: Philosophy in a New Key. Cambridge, Mass.: Harvard University Press.

LEAVIS, F.R.

1948: Education and the University. London: Chatto and Windus. LÉVI-STRAUSS, C.

1968: Structural Anthropology. Translated by Claire Jacobson and Brooke Grundfest Schoepf. Harmondsworth, Middlesex: Penguin Books.

LOVELL, T.

1972: "Sociology of Aesthetic Structures and Contextualism," in McQuail, D., ed., Sociology of Mass Communications. Harmondsworth, Middlesex: Penguin Books, 329-49. 
MÂCHE, F.B.

1973: "Musical Composition Today," Cultures, I/1, 101-11.

MERRIAM, A.P.

1964: The Anthropology of Music. Evanston: Northwestern University Press.

MEYER, L.B.

1956: Emotion and Meaning in Music. Chicago: University of Chicago Press.

1967: Music, the Arts and Ideas. Chicago: University of Chicago Press.

1973: Explaining Music: Essays and Explorations. Berkeley: University of California Press.

PLEASANTS, $\mathrm{H}$.

1969: Serious Music and All That Jazz. London: Victor Gollancz. SHEPHERD, J., VIRDEN, P., VULLIAMY, G., and WISHART, T.

1977: Whose Music? A Sociology of Musical Languages. London:

Latimer New Dimensions; reprinted New Brunswick, N.J.: Transaction Books, 1980.

STEARNS, M.

1956: The Story of Jazz. London: Oxford University Press. WILLIAMS, R.

1961: Culture and Society 1780-1950. Hardmondsworth, Middlesex: Penguin Books.

ZUCKERKANDL, $\mathrm{V}$.

1956: Sound and Symbol: Music and the External World. London: Routledge and Kegan Paul. 